\title{
Critical Assessment of the Use of Excess Lead lodide in Lead Halide Perovskite Solar Cells
}

\author{
Bart Roose,* Krishanu Dey, Yu-Hsien Chiang, Richard H. Friend, and Samuel D. Stranks \\ Cite This: J. Phys. Chem. Lett. 2020, 11, 6505-6512 \\ Read Online
}

ABSTRACT: It is common practice in the lead halide perovskite solar cell field to add a small molar excess of lead iodide $\left(\mathrm{PbI}_{2}\right)$ to the precursor solution to increase the device performance. However, recent reports have shown that an excess of $\mathrm{PbI}_{2}$ can accelerate performance loss. In addition, $\mathrm{PbI}_{2}$ is photoactive (band gap $\sim 2.3 \mathrm{eV}$ ), which may lead to parasitic absorption losses in a solar cell. Here we show that devices using small quantities of excess $\mathrm{PbI}_{2}$ exhibit better device performance as compared with stoichiometric devices, both initially and for the duration of a stability test under operating conditions, primarily by enhancing the charge extraction. However, the photolysis of $\mathrm{PbI}_{2}$ negates the beneficial effect on charge extraction by leaving voids in the perovskite film and introduces trap states that are detrimental for device performance. We propose that although excess $\mathrm{PbI}_{2}$ provides a good template for enhanced performance, the community must continue to seek other additives or synthesis routes that fulfill the same beneficial role as excess $\mathrm{PbI}_{2}$, but without the photolysis that negates these beneficial effects under long-term device operation.

$\mathrm{P}$ erovskite solar cells (PSCs) are rising stars in the photovoltaics field. A combination of ease of processing, cheap and abundant precursors, high absorption coefficients, and long charge-carrier diffusion lengths have led to the rapid development of the PSC field. ${ }^{1}$ The first reports came out only a decade ago, ${ }^{2,3}$ yet power conversion efficiencies (PCEs) now exceed $25 \%$, rivalling that of the established silicon solar cell. ${ }^{4}$ Added to this is the tunability of the band gap through compositional engineering, making perovskites ideal materials for tandem solar cells. ${ }^{5}$ It is thus evident that perovskites will play an important role in future energy generation; however, there is still much room to further improve stability ${ }^{6}$ and push the PCE closer to the theoretical maximum. ${ }^{7}$

One frequently used method to empirically maximize PCE is through ensuring that a small excess of $\mathrm{PbI}_{2}$ is present in the final perovskite absorber layer. This can be achieved by adding a small molar excess of $\mathrm{PbI}_{2}$ (5-10 mol \% with respect to the stoichiometric composition) to the precursor solution ${ }^{8}$ or by heat-treating the perovskite film to generate $\mathrm{PbI}_{2}$ in situ. ${ }^{9}$ Recent reports have shown that excess $\mathrm{PbI}_{2}$ can passivate defects, leading to a higher open-circuit potential $\left(V_{\text {oc }}\right) .^{10-13}$ Furthermore, a key advantage of excess $\mathrm{PbI}_{2}$ has been ascribed to it preventing the formation of an organic-rich surface, which otherwise impedes the charge extraction. ${ }^{8}$ As a result, devices using an excess of $\mathrm{PbI}_{2}$ also exhibit an improved short-circuit current $\left(J_{\text {sc }}\right)^{8,9,14-16}$ In addition, there are reports of excess $\mathrm{PbI}_{2}$ increasing the device stability, in particular, protecting against water- or oxygen-induced degradation. ${ }^{15,17,18}$ However, other recent reports have claimed that excess $\mathrm{PbI}_{2}$ can accelerate device degradation in the presence of oxygen and humidity $^{19,20,16}$ or heat and light. ${ }^{20,21}$ Exposure to oxygen and humidity can be prevented by encapsulation and will not be studied here, but heat and light are unavoidable for a solar cell under operating conditions. Furthermore, some studies found that excess $\mathrm{PbI}_{2}$ has a detrimental effect on the performance ${ }^{22}$ and can cause parasitic absorption. ${ }^{11}$ These apparent contradictions in the field make it difficult to draw universal conclusions about the use of $\mathrm{PbI}_{2}$. Now that PSCs are approaching commercialization, it is important to critically assess the use of excess $\mathrm{PbI}_{2}$ and determine whether it is a practical or a parasitic additive.

This study describes how X-ray diffraction (XRD) and scanning electron microscopy (SEM) can be used to probe excess $\mathrm{PbI}_{2}$ in methylammonium lead iodide perovskite $\left(\mathrm{MAPbI}_{3}\right)$ films and devices. These techniques are used to explore when excess $\mathrm{PbI}_{2}$ is beneficial for performance side-byside with device measurements and optical techniques to investigate any parasitic absorption by $\mathrm{PbI}_{2}$. It is found that low concentrations of excess $\mathrm{PbI}_{2}(\leq 5 \mathrm{~mol} \%$ in the precursor solutions) lead to the presence of predominantly crystalline $\mathrm{PbI}_{2}$. For higher concentrations, large clusters of amorphous $\mathrm{PbI}_{2}$ are observed in the film, and the preferential orientation of the $\mathrm{MAPbI}_{3}$ crystallites changes abruptly. These observations correlate with an increase in the device performance up

Received: June 12, 2020

Accepted: July 22, 2020

Published: July 22, 2020 

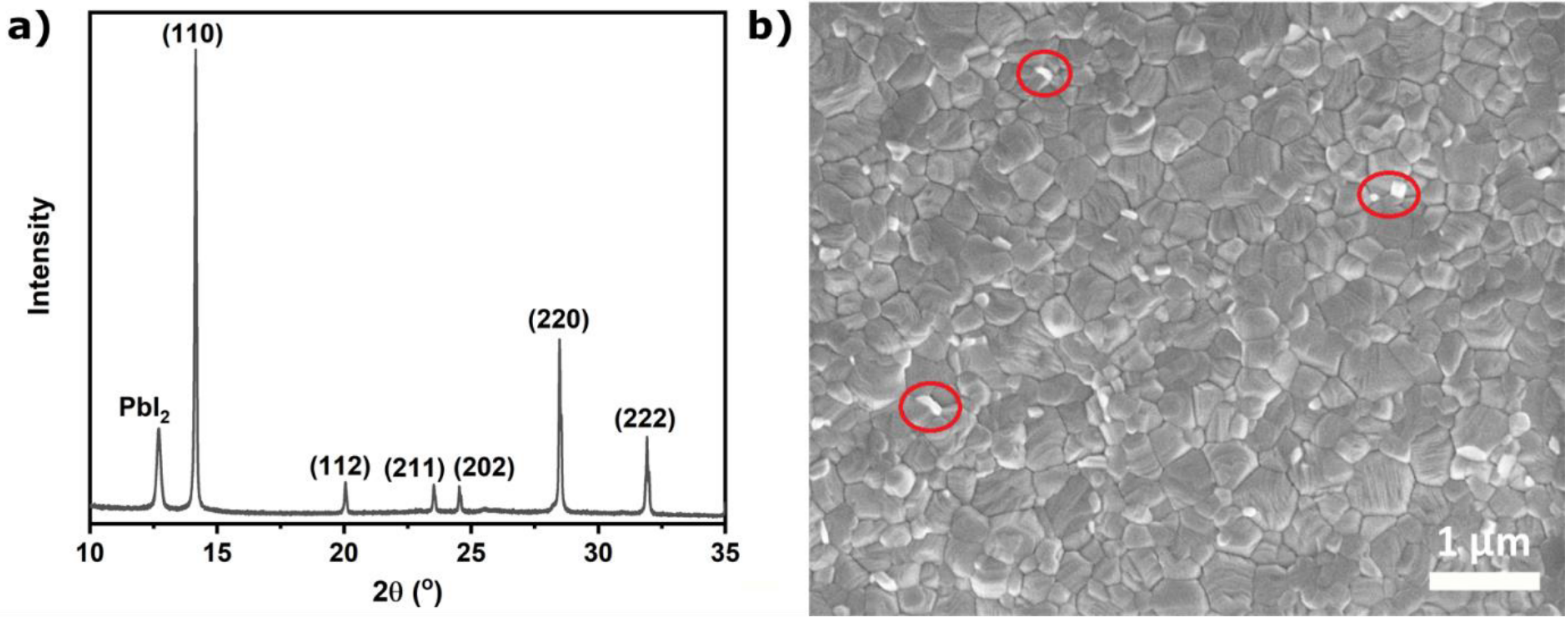

Figure 1. (a) XRD diffractogram of a tetragonal $\mathrm{MAPbI}_{3}$ film containing a $20 \%$ molar excess of $\mathrm{PbI}_{2}$, with the $(001)$ peak of $\mathrm{PbI}_{2}$ at $12.6^{\circ} .{ }^{23}(\mathrm{~b})$ $\mathrm{SEM}$ image of a polycrystalline $\mathrm{MAPbI}_{3}$ film with $10 \mathrm{~mol} \%$ excess $\mathrm{PbI}_{2}$ in $\mathrm{SE}$ mode. $\mathrm{PbI}_{2}$ crystals are brighter than perovskite crystals due to the higher average atomic number; selected $\mathrm{PbI}_{2}$ crystals are circled in red.

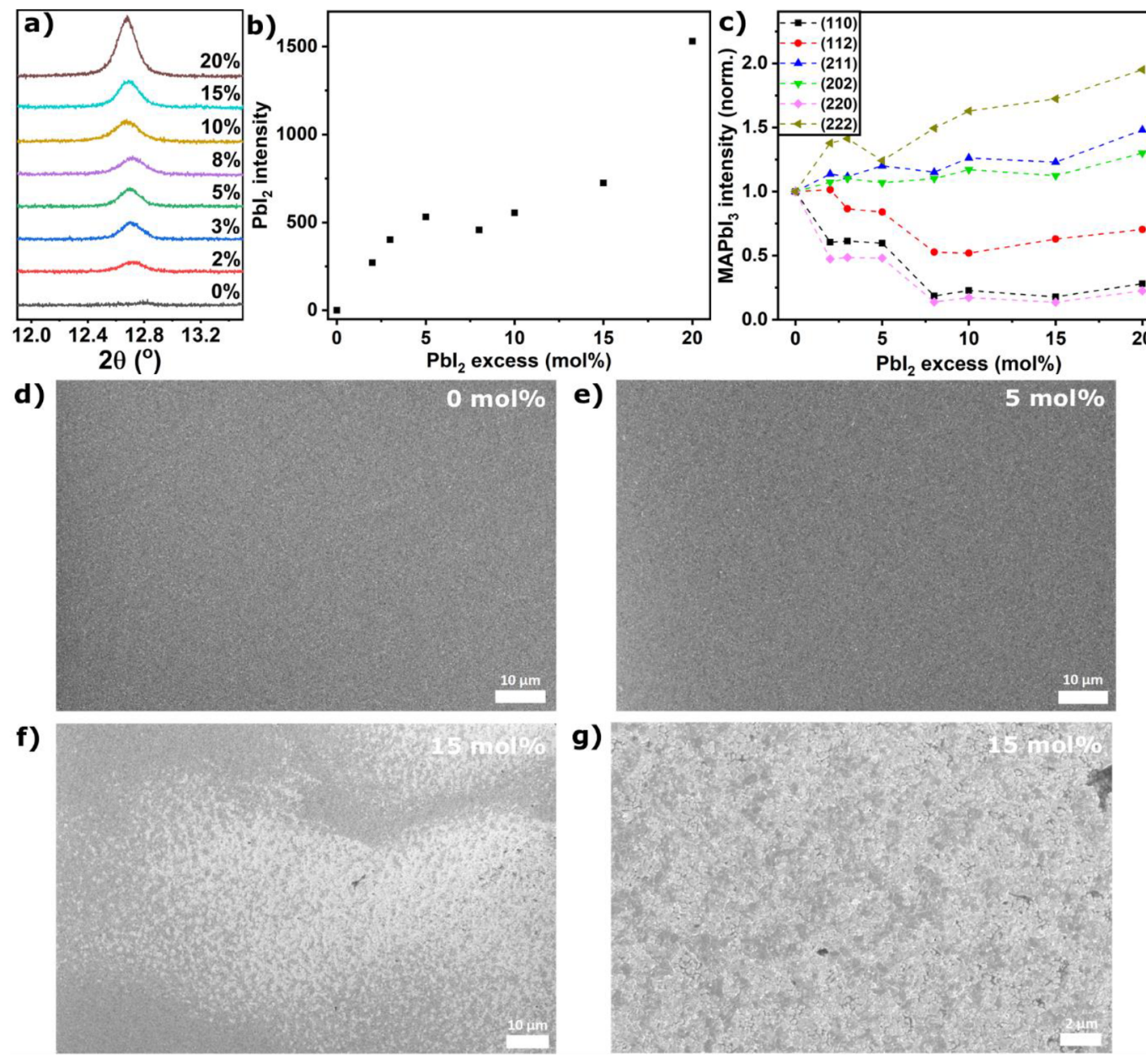

Figure 2. (a) XRD diffractograms (vertically offset for clarity) showing the evolution of the (001) $\mathrm{PbI}_{2}$ diffraction peak in films with increasing molar excess (in mol \%). (b) Peak intensity of the (001) $\mathrm{PbI}_{2}$ diffraction peak extracted from panel a. (c) Normalized intensity of $\mathrm{MAPbI}_{3}$ diffraction peaks, extracted from the diffractograms in Figure S1. SEM image of a (d) stoichiometric $\mathrm{MAPbI}_{3}$ film, (e) $5 \mathrm{~mol} \%$ excess $\mathrm{PbI}_{2}$ film, (f) $15 \mathrm{~mol} \%$ excess $\mathrm{PbI}_{2}$ film, and (g) close-up of a $15 \mathrm{~mol} \%$ excess $\mathrm{PbI}_{2}$ film.

to an excess $\mathrm{PbI}_{2}$ content of $5 \mathrm{~mol} \%$, mainly due to an increase in the short-circuit current $\left(J_{\text {sc }}\right)$, indicating that charge extraction is enhanced. For higher concentrations of excess
$\mathrm{PbI}_{2}$, charge extraction is impeded, and $J_{\mathrm{sc}}$ and thus the device performance drop. Photoluminescence excitation (PLE) and external quantum efficiency (EQE) measurements show that 

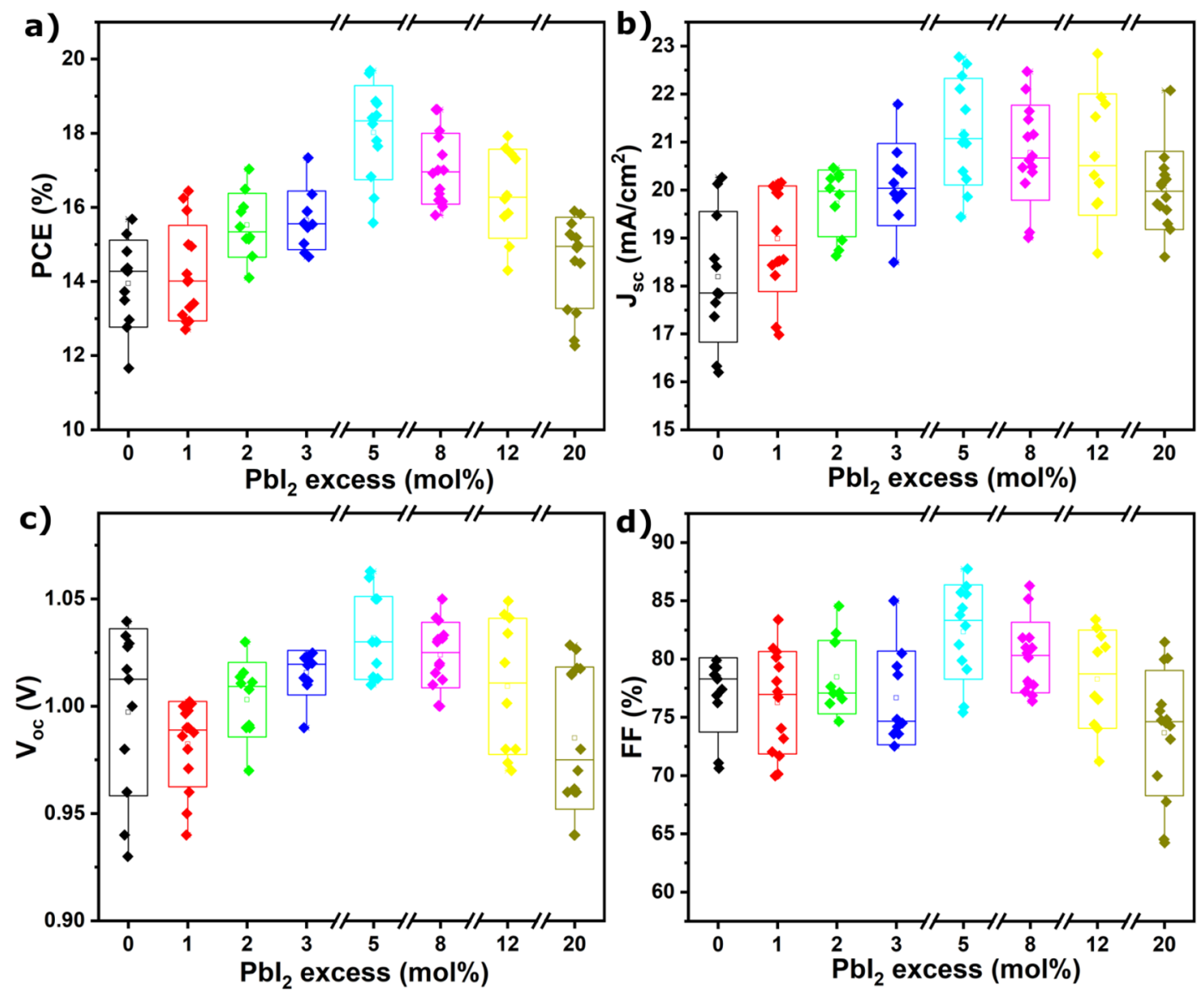

Figure 3. Boxplots of the device parameters of $\mathrm{MAPbI}_{3}$ solar cells as a function of the $\mathrm{PbI}_{2}$ excess in the precursor solution measured from open circuit to short circuit under AM1.5 $100 \mathrm{~mW} / \mathrm{cm}^{2}$. (a) Power conversion efficiency, (b) short-circuit current, (c) open-circuit voltage, and (d) fill factor.

there is no parasitic absorption from $\mathrm{PbI}_{2}$ at concentrations optimized for device performance. Finally, the device operational stability is assessed over periods of hours, again in conjunction with XRD and SEM measurements, to provide further insight into the observed changes in the device performance. Although devices incorporating excess $\mathrm{PbI}_{2}$ outperform their stoichiometric counterparts for the duration of the stability tests, the photolysis of $\mathrm{PbI}_{2}$ negates the positive effect $\mathrm{PbI}_{2}$ has on charge extraction by leaving voids in the perovskite film and introducing new trap states that are detrimental to $V_{\mathrm{oc}}$ and hence the device performance. Our collective results conclusively show that despite the tempting benefits of an improved initial device performance, excess $\mathrm{PbI}_{2}$ should be avoided in the interest of long-term performance, and there is thus a need to develop alternative additives or synthesis routes that render the need for excess $\mathrm{PbI}_{2}$ obsolete.

Solution-processed thin films of $\mathrm{MAPbI}_{3}$ were deposited on glass slides using established recipes ${ }^{24}$ but with precursor solutions containing different molar fractions of excess $\mathrm{PbI}_{2}$ (0-20 mol \%) with respect to the stoichiometric films. (See the Materials and Methods.) We focus on the most widely studied archetypal $\mathrm{MAPbI}_{3}$ system to allow a comparison with the literature reports and to avoid the phase segregation ${ }^{25}$ often seen in mixed-halide systems that can obscure the effects caused by excess $\mathrm{PbI}_{2}$. The most widely used method to detect the presence of crystalline $\mathrm{PbI}_{2}$ in a perovskite film is $\mathrm{XRD}$, which is able to detect quantities of crystalline entities on the order of a few percent by mass. ${ }^{26}$ The (001) diffraction peak of hexagonal $\mathrm{PbI}_{2}$ at $2 \theta=12.6^{\circ}$ can clearly be distinguished from the tetragonal perovskite peaks (Figure 1a). The penetration depth of X-rays in perovskite is $>10 \mu \mathrm{m},{ }^{27}$ allowing XRD to probe the entire $\mathrm{MAPbI}_{3}$ film, which is typically $<500 \mathrm{~nm}$ thick. XRD is used not only to detect initial quantities of unreacted $\mathrm{PbI}_{2}$ in perovskite films but also to study degradation, as $\mathrm{PbI}_{2}$ is one of the main degradation products of lead halide perovskites.

Although XRD can detect the presence of crystalline $\mathrm{PbI}_{2}$ throughout the perovskite film, it cannot detect amorphous phases. A complementary characterization method that can show the presence of $\mathrm{PbI}_{2}$ is SEM. In the lead halide perovskite field, SEM is typically used in a mode that is optimized for the detection of secondary electrons, which only carry topological information. However, a fraction of backscattered electrons will also be detected, which give compositional information. The intensity of backscattered electrons is dependent on the atomic number of the atoms in the sample, with areas having a higher average atomic number showing up brighter in typical images. This is observed in films containing an excess of $\mathrm{PbI}_{2}$, for instance, in the $\mathrm{MAPbI}_{3}$ film with $10 \mathrm{~mol} \%$ excess $\mathrm{PbI}_{2}$ shown in Figure $1 \mathrm{~b}$; bright $\mathrm{PbI}_{2}$ crystals can be seen on the surface, as $\mathrm{PbI}_{2}$ has a higher average atomic number than the surrounding $\mathrm{MAPbI}_{3}$ perovskite. As such, SEM can also be used to detect the presence of $\mathrm{PbI}_{2}$. In contrast with $\mathrm{XRD}$, SEM can detect amorphous as well as crystalline phases, but it predominantly characterizes the surface of the film. Thus XRD and SEM together provide an excellent probe of $\mathrm{PbI}_{2}$. 

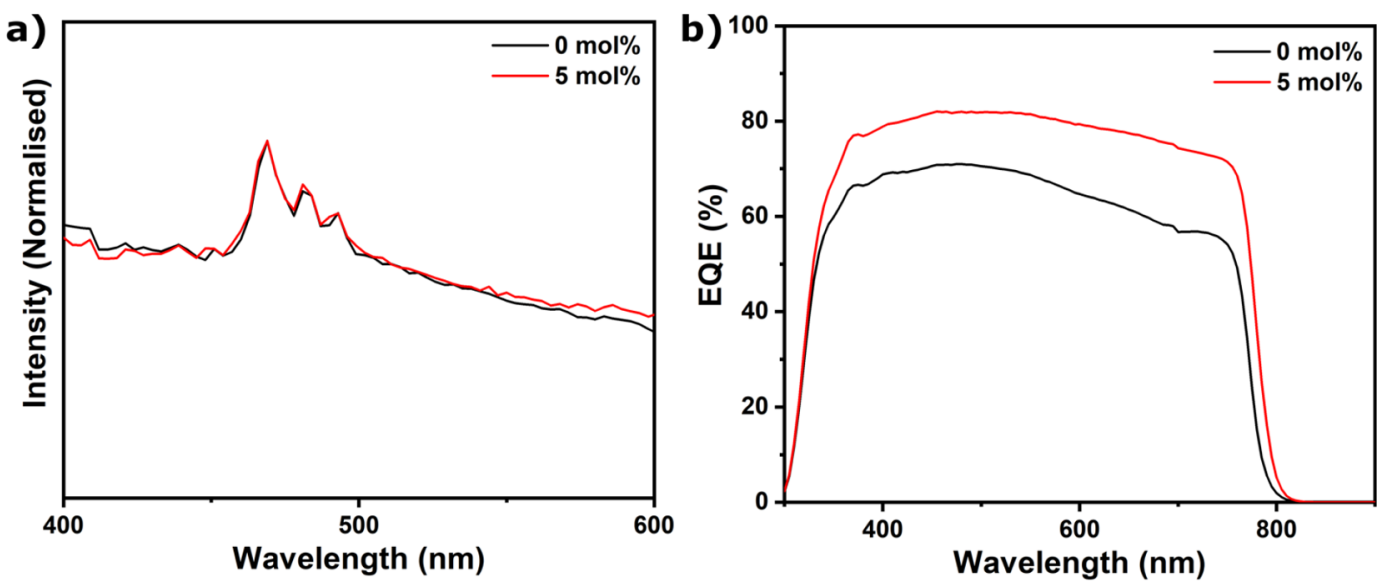

Figure 4. (a) PLE spectra for $\mathrm{MAPbI}_{3}$ films and (b) EQE spectra for solar cells using a stoichiometric $(0 \mathrm{~mol} \%)$ and a 5 mol \% excess $\mathrm{PbI}_{2}$ precursor solution.

Figure $2 \mathrm{a}$ shows the (001) diffraction peak of $\mathrm{PbI}_{2}$, and Figure $2 \mathrm{~b}$ shows the intensity of this peak as a function of the excess $\mathrm{PbI}_{2}$ in the $\mathrm{MAPbI}_{3}$ precursor solution. (See Figure $\mathrm{S} 1$ for full XRD diffractograms.) The crystalline (001) $\mathrm{PbI}_{2}$ peak can be seen to increase in intensity monotonically up to $5 \mathrm{~mol}$ $\%$ excess $\mathrm{PbI}_{2}$, after which it plateaus and does not start increasing again until $\sim 15 \mathrm{~mol} \%$. We hypothesize that the extra $\mathrm{PbI}_{2}$ added after $5 \mathrm{~mol} \%$ may not crystallize but is instead present as an amorphous phase. The intensity of the individual perovskite peaks, relative to the stoichiometric sample (set to 1), is shown in Figure $2 \mathrm{c}$ as a function of the $\mathrm{PbI}_{2}$ excess in the precursor solution. The dominant (110) and (220) diffraction peaks show a significant drop in intensity at $\mathrm{PbI}_{2}$ excess concentrations beyond $5 \mathrm{~mol} \%$, indicating that $\mathrm{PbI}_{2}$ can influence the preferential orientation of $\mathrm{MAPbI}_{3}$ crystals when it reaches a critical concentration. However, the presence of $\mathrm{PbI}_{2}$ does not seem to have a significant effect on the average $\mathrm{MAPbI}_{3}$ crystallite size, as ascertained from the full width at half-maximum values of the perovskite XRD peaks (Figure S2) and is consistent with SEM images (Figure S3). Impurities have been shown to slow the crystal growth, ${ }^{28}$ which will especially affect the fast growing preferential orientations but not necessarily the final crystallite size.

Despite minimal grain size changes, quite dramatic changes are observed in films made with $>5 \mathrm{~mol} \%$ excess $\mathrm{PbI}_{2}$ in the precursor solution. Films containing low concentrations of excess $\mathrm{PbI}_{2}$ are very uniform, as observed in SEM images (Figure 2d,e). However, films with $>5 \mathrm{~mol} \%$ excess $\mathrm{PbI}_{2}$ exhibit increasingly large (tens of micrometer) patches with high concentrations of $\mathrm{PbI}_{2}$, showing up as brighter regions in the SEM image (Figure $2 \mathrm{f}$ for $15 \mathrm{~mol} \%$ ). A closer look at these patches (Figure $2 \mathrm{~g}$ ) reveals a mostly conformal layer of $\mathrm{PbI}_{2}$. The appearance of this $\mathrm{PbI}_{2}$ layer is very different from the distinct $\mathrm{PbI}_{2}$ crystallites that can be seen in Figure $1 \mathrm{~b}$, and we propose that this covering corresponds to the amorphous $\mathrm{PbI}_{2}$ implied by the plateau of intensity in XRD. Assuming conformal $\mathrm{PbI}_{2}$ coverage of each entire grain (each on the order of several hundred nanometers in diameter; cf. Figures $\mathrm{S} 2$ and S3), this would result in a $\mathrm{PbI}_{2}$ layer that is $<5 \mathrm{~nm}$ thick for $5 \mathrm{~mol} \%$ excess (Table S4). Given the large $\mathrm{PbI}_{2}$ crystallites that are observed by SEM and XRD, not all of the excess $\mathrm{PbI}_{2}$ will form a conformal layer, and thus the $\mathrm{PbI}_{2}$ surface layer is likely much thinner in many places and below the detection limit of SEM.
PSCs were fabricated with the device stack consisting of fluorine-doped tin-oxide (FTO)-coated glass as the front electrode, compact and mesoporous $\mathrm{TiO}_{2}$ as electron-transporting material, $\mathrm{MAPbI}_{3}$ with different quantities of excess $\mathrm{PbI}_{2}$ as the light absorbing material, $\mathrm{N}^{2}, \mathrm{~N}^{2}, \mathrm{~N}^{2 \prime}, \mathrm{N}^{2 \prime}, \mathrm{N}^{7}, \mathrm{~N}^{7}, \mathrm{~N}^{7 \prime}, \mathrm{N}^{7 \prime}$-octakis(4-methoxyphenyl)-9,9' spirobi[9H-fluorene]-2, $2^{\prime}, 7,7^{\prime}$-tetramine (spiro-OMeTAD) as the hole-transporting material, and gold as the back electrode. (See the Materials and Methods.) Statistics of extracted device parameters are shown in Figure 3 (see Table S5 for further details), where an excess of $5 \mathrm{~mol} \% \mathrm{PbI}_{2}$ is found to give the highest PCE (Figure 3a). This is primarily due to an increase in $J_{s c}$ compared with the stoichiometric control, whereas no significant changes in the open-circuit voltage $\left(V_{o c}\right)$ or fill factor (FF) are observed. These findings are in agreement with the observations of Jacobsson et al., ${ }^{8}$ who attribute the increased device performance primarily to improved electron injection from the perovskite into the electron extracting layer, leading to a higher $J_{s c}$. Our study finds that the subsequent drop in $J_{\text {sc }}$ for higher $\mathrm{PbI}_{2}$ excess concentrations is likely related to the amorphous $\mathrm{PbI}_{2}$ patches observed with SEM (Figure $2 \mathrm{f}, \mathrm{g}$ ). A conformal layer of $\mathrm{PbI}_{2}$ can act as an insulating layer, ${ }^{8}$ preventing charge extraction from these areas and explaining the drop in $J_{s c}$ found in solar cells with $>5 \mathrm{~mol} \% \mathrm{PbI}_{2}$. Additionally, the changes in the preferred orientation (Figure $2 c)$, specifically the relative reduction in the (110), (220), and (112) $\mathrm{MAPbI}_{3} \mathrm{XRD}$ peaks, coincide with the drop in $J_{\mathrm{sc}}$ observed in solar cells (Figure 3b). Previous studies have shown that the (110) surface facilitates electron transfer from $\mathrm{MAPbI}_{3}$ to the electron-collecting contact, whereas the (112) surface facilitates hole injection into the hole-collecting contact. $^{29}$ Both of these orientations become less prominent for $\mathrm{PbI}_{2}$ excess concentrations above $5 \mathrm{~mol} \%$, leading to less efficient charge extraction and a lower $J_{\mathrm{sc}}$.

A weak passivation effect is also observed, with the photoluminescence quantum efficiency (PLQE) of representative films increasing from $0.02 \%$ for $0 \mathrm{~mol} \%$ excess $\mathrm{PbI}_{2}$ to $0.05 \%$ for $5 \mathrm{~mol} \%$ excess $\mathrm{PbI}_{2}$. This would correspond to a negligibly small $V_{\text {oc }}$ increase $(\sim 20 \mathrm{mV}$, Table S6), which is within the standard deviation of the measured $V_{\text {oc }}$ and consistent with no significant improvement in $V_{\text {oc }}$. We note that the PLQE reaches a maximum for $2 \mathrm{~mol} \%$ excess, indicating that for passivation alone, lower concentrations of excess $\mathrm{PbI}_{2}$ are sufficient (Table S6); this passivation effect 

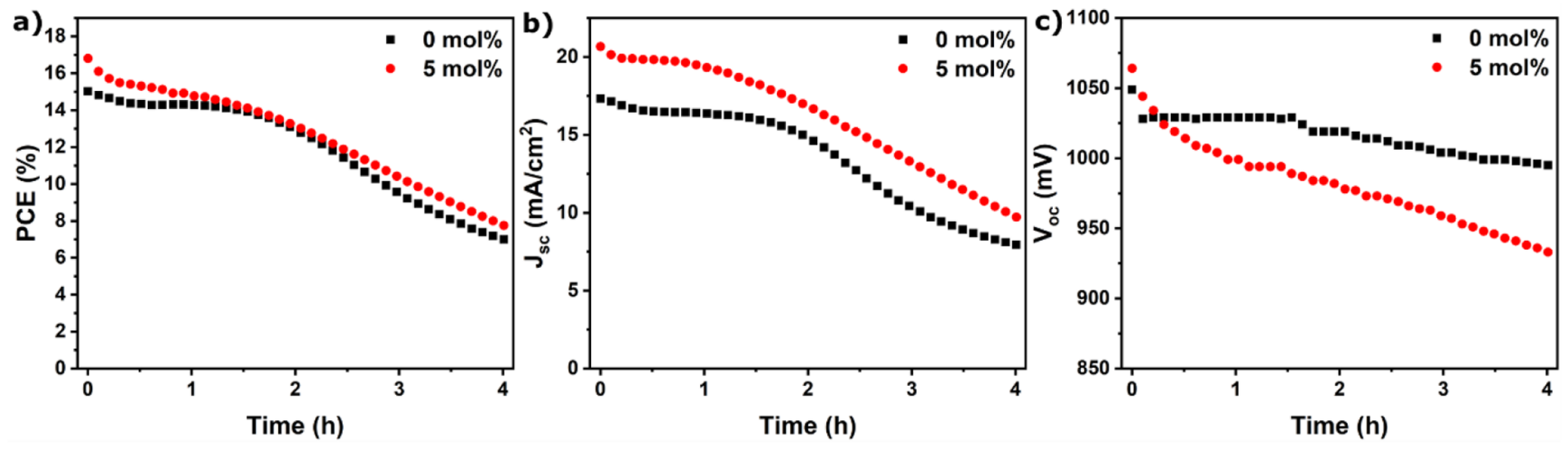

Figure 5. Device parameters of stoichiometric $(0 \mathrm{~mol} \%)$ and $5 \mathrm{~mol} \%$ excess $\mathrm{PbI}_{2} \mathrm{MAPbI}_{3}$ solar during a 4 h stability test under continuous $J-V$ sweeping (from open circuit to short circuit) in an inert atmosphere: (a) PCE, (b) $J_{\text {sc }}$ and (c) $V_{\text {oc }}$.
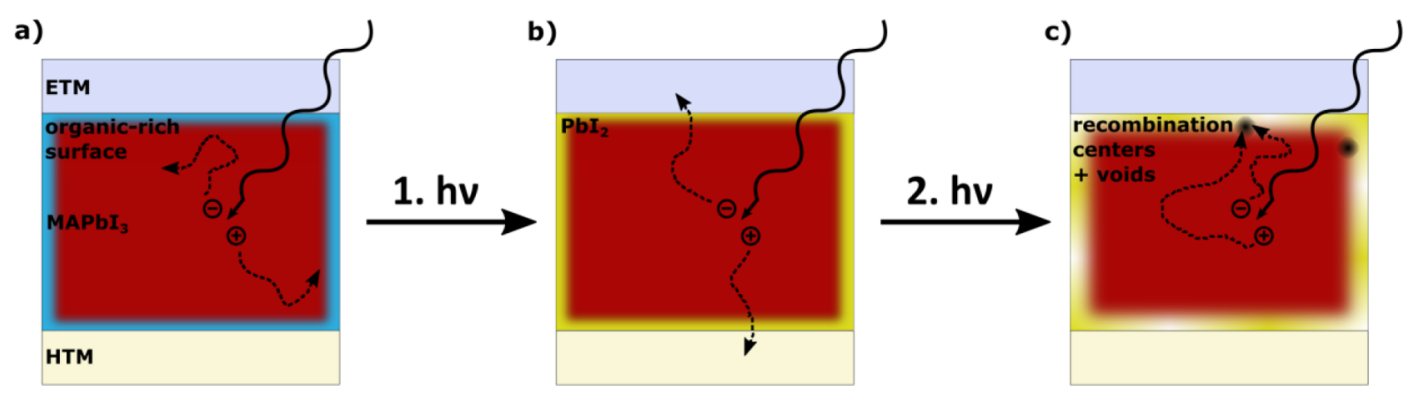

Figure 6. Schematic representation of the effect of $\mathrm{PbI}_{2}$ on the device performance. $\mathrm{MAPbI}_{3}$ grain in a stoichiometric film, sandwiched between an electron-transporting material (ETM) and a hole-transporting material (HTM). (a) An organic-rich surface layer impedes the charge extraction of photoexcited charge carriers. (b) Under continuous illumination, $\mathrm{MAPbI}_{3}$ is decomposed, generating $\mathrm{PbI}_{2}$, which facilitates charge extraction. (c) Simultaneously, the photolysis of $\mathrm{PbI}_{2}$ leaves voids that negate its beneficial effect on charge collection and creates recombination centers. Note that photolysis will occur as soon as excess $\mathrm{PbI}_{2}$ is generated and that the stoichiometric film will thus never reach a state comparable to that of a film with a preloaded excess of $\mathrm{PbI}_{2}$.

may be the result of an extremely thin surface layer of $\mathrm{PbI}_{2}$ that is below detection levels in SEM (Figure S3b).

Figure $4 \mathrm{a}$ shows the normalized PLE spectra for stoichiometric films and films with the optimal $\mathrm{PbI}_{2}$ content for device performance, that is, $5 \mathrm{~mol} \%$ excess $\mathrm{PbI}_{2}$. It can be clearly seen that there is no dip in intensity below $520 \mathrm{~nm}$ for devices using an excess of $\mathrm{PbI}_{2}$, which would otherwise be observed for thick ( $>100 \mathrm{~nm}$ ) layers of $\mathrm{PbI}_{2}$ in the direct absorption path of incident photons. ${ }^{11}$ EQE measurements (Figure 4b) further corroborate that there is no parasitic absorption in that region for excess $\mathrm{PbI}_{2}$ at concentrations relevant for solar cell operation. This observation can be rationalized by considering where the $\mathrm{PbI}_{2}$ is situated: SEM suggests that a large fraction of the $\mathrm{PbI}_{2}$ segregates out at the top surface, and most of the incident light (including below $520 \mathrm{~nm}$ ) would be absorbed by the $\sim 500 \mathrm{~nm}$ thick layer of MAPbI ${ }_{3}$ before it reaches the $\mathrm{PbI}_{2} \cdot{ }^{30}$ The EQE measurements also validate the enhanced current densities in the samples with $5 \mathrm{~mol} \%$ excess $\mathrm{PbI}_{2}$ over their stoichiometric analogues. In the EQE spectrum, a slight red shift of the absorption onset can be seen for the $5 \mathrm{~mol} \%$ excess sample. This shift is also observed in PL emission spectra (Figure S7) and has been found for other surface passivation strategies. ${ }^{31}$ This may also contribute to the drop in $V_{\text {oc }}$ found for 1 mol \% excess $\mathrm{PbI}_{2}$ devices compared with their stoichiometric counterparts.

To assess the impact of excess $\mathrm{PbI}_{2}$ on the device stability, stoichiometric and $5 \mathrm{~mol} \%$ excess $\mathrm{PbI}_{2} \mathrm{MAPbI}_{3}$ solar cells were subjected to a stability test under operating conditions in an inert atmosphere. Both stoichiometric and $5 \mathrm{~mol} \%$ excess
$\mathrm{PbI}_{2}$ devices show an initial drop in PCE in the first $20 \mathrm{~min}$, followed by a plateau phase for $\sim 60 \mathrm{~min}$ in which the performance is steadier before the performance again rapidly reduces after $\sim 1.5 \mathrm{~h}$ (Figure $5 \mathrm{a}$ ). The plateau phase is flatter and lasts longer for stoichiometric devices, although devices with excess $\mathrm{PbI}_{2}$ still retain a higher PCE over the duration of the stability test. Overall, the loss of performance can mainly be attributed to a decrease in current (Figure $5 b$ ), as $J_{\text {sc }}$ shows an initial drop, followed by a plateau, and then further degradation. The $V_{\text {oc }}$ also exhibits an initial drop for both samples, and this is followed by a more gradual decay that only marginally contributes to the performance loss; this decay in the $V_{\mathrm{oc}}$ is, however, more pronounced in the $5 \mathrm{~mol} \%$ excess $\mathrm{PbI}_{2}$ device.

The observed trends can be explained by considering the initial film composition and several decomposition pathways. In the stoichiometric device, an organic rich surface is present that impedes the charge extraction ${ }^{8}$ (Figure 6a), whereas in the $5 \mathrm{~mol} \%$ excess device, the $\mathrm{PbI}_{2}$-enriched surface ensures good charge extraction. The initial drop in the device performance of both samples can be ascribed to a burn-in process related to processes in the charge-collecting contacts or their interfaces with the perovskite. ${ }^{32}$ To explain the plateau phase, two processes have to be taken into account; (i) decomposition of $\mathrm{MAPbI}_{3}$ into $\mathrm{PbI}_{2}, \mathrm{CH}_{3} \mathrm{NH}_{2}$, and $\mathrm{HI}$, ${ }^{33}$ where the latter two leave the film as gases (Figure 6, step 1), and (ii) photolysis of $\mathrm{PbI}_{2}$ (cf. Figures $\mathrm{S} 9$ and $\mathrm{S} 10$ ) into $\mathrm{Pb}(0)$ and $\mathrm{I}_{2}$ gas $^{21}$ (Figure 6 , step 2). The decomposition of $\mathrm{MAPbI}_{3}$ may have a beneficial effect by generating $\mathrm{PbI}_{2}$, ${ }^{15}$ which facilitates 
improved charge collection up until a critical $\mathrm{PbI}_{2}$ threshold (cf. Figure 6b). This in situ generation of $\mathrm{PbI}_{2}$ would be especially beneficial for the stoichiometric device, consistent with the more extended device performance plateau phase in Figure 5a, also considering evidence that $\mathrm{PbI}_{2}$ is mainly formed at interfaces. ${ }^{9}$ At the same time, the gaseous decomposition products leave the film, creating voids that obstruct the charge collection. ${ }^{21}$ Additionally, $\mathrm{Pb}(0)$ acts as a recombination center, ${ }^{21}$ in which case an excess of $\mathrm{PbI}_{2}$ would lead to the formation of more $\mathrm{Pb}(0)$ and thus more nonradiative recombination (Figure 6c), leading to a drop in $V_{\text {oc }}$ (Figure $5 \mathrm{c})$. For $5 \mathrm{~mol} \%$ excess $\mathrm{PbI}_{2}$, the first process is less beneficial, as the optimal $\mathrm{PbI}_{2}$ content is already preloaded, and the second process of $\mathrm{PbI}_{2}$ degradation starts to play a significant role in an earlier stage. This is manifested in the faster drop in $V_{\text {oc }}$ for $5 \mathrm{~mol} \%$ excess $\mathrm{PbI}_{2}$ and the shorter duration of the plateau phase as compared with stoichiometric devices. At the plateau phase, the combined beneficial and detrimental effects of these processes are balanced, leading to no net change in PCE or $J_{\text {sc }}$. When a critical amount of decomposition has taken place, the beneficial effect of $\mathrm{PbI}_{2}$ generation can no longer make up for the reduction in absorption and charge extraction and the generation of defects (Figure 6c), and as a result, the device performance dramatically decreases. Even though the relative loss of performance is larger for excess $\mathrm{PbI}_{2}$ devices, the absolute performance is higher over the duration of the stability test. To investigate whether these observations are more generally applicable to lead halide perovskites, a stability test was performed on devices containing cesium formamidinium lead iodide $\left(\mathrm{Cs}_{0.1} \mathrm{FA}_{0.9} \mathrm{PbI}_{3}\right)$ as the light -absorbing material (Figure S8). Because this material is more stable under operating conditions than $\mathrm{MAPbI}_{3}{ }^{34}$ very little $\mathrm{PbI}_{2}$ is produced by degradation. In this case, poor charge extraction and a resulting low $J_{s c}$ are expected throughout the stability test for stoichiometric devices, whereas for excess $\mathrm{PbI}_{2}$ devices, $J_{\mathrm{sc}}$ is expected to show an initial drop as $\mathrm{PbI}_{2}$ is decomposed and charge extraction is obstructed. $V_{\mathrm{oc}}$ is expected to be stable in the stoichiometric devices, whereas an initial drop is expected in excess devices as excess $\mathrm{PbI}_{2}$ is decomposed. The stability tests in Figure S8 show that this is indeed the case. (See Figure S8 for a more in-depth discussion.)

This study is making clear that additives intended to passivate surfaces and interfaces need to follow a number of design rules if they are to be used in PSCs. These additives must not absorb any sizable fraction of the light that reaches the light-absorbing layer, as this can lead to parasitic absorption and potentially degradation of the additive, which negate the beneficial effects of the additive by creating voids in the film and may introduce recombination centers, limiting long-term stability. Secondly, any additives should have a lower tendency to crystallize or self-aggregate so that they can be delivered where they are needed instead of forming large crystallites; even if they are inert, they may have detrimental effects, for example, through structure deformation. Finally, any additive should promote the preferential growth of crystal planes that are beneficial for charge extraction. Although $\mathrm{PbI}_{2}$ provides some beneficial properties within a narrow concentration window, the fact it is produced as a degradation product of the $\mathrm{MAPbI}_{3}$ absorber, and the fact that it can also degrade to yield recombination centers, renders it detrimental in the long term.

This study provides a detailed account of how excess $\mathrm{PbI}_{2}$ can be detected in lead halide perovskite films and how it affects solar cell device performance and stability. It is found that excess $\mathrm{PbI}_{2}$ increases the device performance mainly by facilitating improved charge extraction. PLE and EQE show that there is no parasitic absorption at optimized excess $\mathrm{PbI}_{2}$ concentrations. Amorphous $\mathrm{PbI}_{2}$ covers large areas of the perovskite film for higher $\mathrm{PbI}_{2}$ concentrations, forming an insulating layer that, in combination with reduced preferential orientation, impedes charge extraction and leads to a loss of performance. Stability tests show that even though performance loss is more pronounced for excess $\mathrm{PbI}_{2}$ devices, they do outperform stoichiometric devices for the duration of the tests performed here. However, the photolysis of $\mathrm{PbI}_{2}$ negates its beneficial effect on charge extraction by leaving voids in the film, and it creates recombination sites, which, in turn, degrade the $V_{\mathrm{oc}}$ of the device. It is shown that these results hold true for other lead halide perovskites besides $\mathrm{MAPbI}_{3}$, as excess $\mathrm{PbI}_{2}$ is shown to be beneficial in alternative compositions, ${ }^{8,10}$ and they also generate $\mathrm{PbI}_{2}$ upon degradation. ${ }^{35}$ Other additives or synthesis protocols that do not require an excess of $\mathrm{PbI}_{2}$ to facilitate charge extraction ${ }^{20,22}$ may provide viable alternatives to the use of excess $\mathrm{PbI}_{2}$ in PSCs to achieve efficient and stable devices.

\section{MATERIALS AND METHODS}

Methylammonium iodide (MAI) and titania paste (30NR-D) were purchased from Greatcell Solar, $\mathrm{PbI}_{2}$ was purchased from TCI, and spiro-OMeTAD was purchased from Borun Technology. All other chemicals were purchased from SigmaAldrich.

Solar Cell Fabrication. FTO-coated glass was cleaned by sonication in $2 \%$ Hellmanex III solution for $15 \mathrm{~min}$, rinsed with deionized water, and sonicated in isopropanol for $15 \mathrm{~min}$. Substrates were dried and transferred to a hot plate and heated to $450{ }^{\circ} \mathrm{C}$. Compact $\mathrm{TiO}_{2}$ was deposited by spray pyrolysis of a solution containing $9 \mathrm{~mL}$ of ethanol, $0.6 \mathrm{~mL}$ of titanium(IV) diisopropoxide bis(acetylacetonate), and $0.4 \mathrm{~mL}$ of acetylacetone. Substrates were cooled to room temperature before the mesoporous $\mathrm{TiO}_{2}(150 \mathrm{mg} / \mathrm{mL}$ paste in ethanol) was deposited by spin-coating (4000 rpm, $10 \mathrm{~s}, 2000 \mathrm{rpm}$ ramp). After spin-coating, the substrates were transferred to a hot plate preheated to $125^{\circ} \mathrm{C}$, and the following protocol was used for annealing: $10 \mathrm{~min}$ at $125^{\circ} \mathrm{C}, 15 \mathrm{~min}$ ramp and $5 \mathrm{~min}$ dwell at $325{ }^{\circ} \mathrm{C}, 5 \mathrm{~min}$ ramp and $5 \mathrm{~min}$ dwell at $375^{\circ} \mathrm{C}$, and $5 \mathrm{~min}$ ramp and $30 \mathrm{~min}$ dwell at $450{ }^{\circ} \mathrm{C}$. Substrates were then allowed to cool to $150{ }^{\circ} \mathrm{C}$, after which they were transferred to a $\mathrm{N}_{2}$-filled glovebox for perovskite deposition. $\mathrm{MAPbI}_{3}$ perovskite precursor solution was prepared by dissolving MAI (1.35 M) and $\mathrm{PbI}_{2}(1.35 \mathrm{M})$ in $N, N$-dimethylformamide/ dimethyl sulfoxide (DMF/DMSO 9:1 vol \%). $\mathrm{Cs}_{0.1} \mathrm{FAPbI}_{3}$ perovskite precursor solution was prepared by dissolving FAI (1.08 M), CsI (0.12 M), and $\mathrm{PbI}_{2}(1.2 \mathrm{M})$ in DMF/DMSO (4:1 vol \%). The required excess $\mathrm{PbI}_{2}$ concentrations were achieved by adding additional $\mathrm{PbI}_{2}$ from a $1.35 \mathrm{M}$ stock, and to keep the $\mathrm{MAPbI}_{3}$ molarity equal for all concentrations, appropriate amounts of DMF/DMSO were added. $\mathrm{MAPbI}_{3}$ was deposited on the substrate by spin-coating (3000 rpm for $20 \mathrm{~s}$ ), and the film was quenched with a stream of $\mathrm{N}_{2} 10 \mathrm{~s}$ into the process. The substrates were then transferred to a hot plate preheated to $100{ }^{\circ} \mathrm{C}$ and annealed for $10 \mathrm{~min} .{ }^{24} \mathrm{Cs}_{0.1} \mathrm{FAPbI}_{3}$ was deposited on the substrate by spin-coating (1000 rpm for $10 \mathrm{~s}, 4000 \mathrm{rpm}$ for $30 \mathrm{~s}$ ), and the film was quenched by dropping chlorobenzene $25 \mathrm{~s}$ into the process. The substrates were then transferred to a hot plate preheated to $150{ }^{\circ} \mathrm{C}$ and 
annealed for $10 \mathrm{~min}^{34}$ After cooling to room temperature, spiro-OMeTAD (0.07 $\mathrm{M}$ in chlorobenzene, doped with $t$ butylpyridine $(3.3 \mathrm{~mol} / \mathrm{mol})$, bis(trifluoromethane)sulfonamide lithium $(0.5 \mathrm{~mol} / \mathrm{mol})$, and tris $(2-(1 \mathrm{H}$-pyrazol1-yl)-4-tert-butylpyridine )-cobalt( III) tris (bis (trifluoromethylsulfonyl)imide) $(0.05 \mathrm{~mol} / \mathrm{mol}))$ was deposited by spin-coating $(4000 \mathrm{rpm}, 20 \mathrm{~s})$. Devices were finished by the thermal evaporation of $100 \mathrm{~nm}$ gold.

Optoelectronic Characterization. A solar simulator from ABET Technologies (model 11016 Sun 2000) with a xenon arc lamp was used to illuminate the solar cells for $J-V$ measurements, which were recorded using a Keithley 2635 sourcemeter. $J-V$ measurements were recorded at a scan speed of $50 \mathrm{mV} / \mathrm{s}$ from open-circuit to short-circuit conditions. Stability measurements were performed using an Autolab PGSTAT302N apparatus by continuously sweeping from open circuit to short circuit at 10 $\mathrm{mV} / \mathrm{s}$.

The measurement and calculation of PLQE were performed according to the literature. ${ }^{36}$ Measurements were conducted using a $520 \mathrm{~nm}$ continuous laser to excite the samples with an excitation power density of $60 \mathrm{~mW} / \mathrm{cm} 2$ (one sun equivalent). The samples were mounted in an integrating sphere (in air) during the excitation, and the PL signal was directed by an optical fiber to an Andor iDus Si Detector. The accumulation time for each measurement was $60 \mathrm{~s}$.

PLE measurements were performed using a $450 \mathrm{~W}$ continuous xenon arc lamp and an Edinburgh Instruments FLS980 fluorimeter. During the measurements, the emission wavelength was fixed at $770 \mathrm{~nm}$, and the excitation wavelength was varied in the range of $450-800 \mathrm{~nm}$, with a wavelength step of $1 \mathrm{~nm}$ and a dwell time of $0.1 \mathrm{~s}$.

$X$-ray Diffraction. X-ray diffractograms of perovskite films were obtained in Bragg-Brentano geometry using a Bruker D8 Advance X-ray diffractometer with $\mathrm{Cu} \mathrm{K} \alpha$ radiation $(\lambda=$ $1.5418 \AA$ ). . All of the measurements were performed with $2 \theta$ angles ranging from 10 to $40^{\circ}$, with a step size of $0.00214^{\circ}$.

Scanning Electron Microscopy. SEM was performed using a Zeiss LEO 1550 FE-SEM apparatus with a field-emission source operating at $2 \mathrm{kV}$ acceleration voltage in the In-Lens mode.

\section{ASSOCIATED CONTENT}

\section{s) Supporting Information}

The Supporting Information is available free of charge at https://pubs.acs.org/doi/10.1021/acs.jpclett.0c01820.

Full XRD diffractograms, fwhm values, and SEM images of $\mathrm{MAPbI}_{3}$ films for different excess $\mathrm{PbI}_{2}$ concentrations; calculation of $\mathrm{PbI}_{2}$ surface layer thickness; device parameters, calculation of $V_{\text {oc }}$ from PLQE; PL emission spectra for stoichiometric and excess $\mathrm{PbI}_{2} \mathrm{MAPbI}_{3}$ films; stability test and $J-V$ curves for $\mathrm{Cs}_{0.1} \mathrm{FA}_{0.9} \mathrm{PbI}_{3}$ devices; and SEM and XRD of films before and after illumination (PDF)

\section{AUTHOR INFORMATION}

\section{Corresponding Author}

Bart Roose - Department of Chemical Engineering and Biotechnology and Department of Physics, Cavendish Laboratory, University of Cambridge, Cambridge CB3 OAS, United Kingdom; (1) orcid.org/0000-0002-0972-1475; Email: br340@cam.ac.uk

\section{Authors}

Krishanu Dey - Department of Physics, Cavendish Laboratory, University of Cambridge, Cambridge CB3 OHE, United Kingdom

Yu-Hsien Chiang - Department of Physics, Cavendish Laboratory, University of Cambridge, Cambridge CB3 OHE, United Kingdom

Richard H. Friend - Department of Physics, Cavendish Laboratory, University of Cambridge, Cambridge CB3 OHE, United Kingdom; 이이.org/0000-0001-6565-6308

Samuel D. Stranks - Department of Chemical Engineering and Biotechnology and Department of Physics, Cavendish Laboratory, University of Cambridge, Cambridge CB3 OAS, United Kingdom; (1) orcid.org/0000-0002-8303-7292

Complete contact information is available at:

https://pubs.acs.org/10.1021/acs.jpclett.0c01820

\section{Notes}

The authors declare the following competing financial interest(s): S.D.S. is a cofounder of Swift Solar, Inc.

\section{ACKNOWLEDGMENTS}

B.R. acknowledges the support of the Royal Society (Newton International Fellowship NF170520). K.D. acknowledges the support of the Cambridge Trust in the form of Cambridge India Ramanujan Scholarship. Y.-H.C. acknowledges the support of the Cambridge Trust. S.D.S. acknowledges support from the Royal Society and Tata Group (UF150033). The authors acknowledge the EPSRC (grant no. EP/T02030X/1 and EP/R023980/1) for funding. The work has received funding from the European Research Council under the European Union's Horizon 2020 research and innovation programme (HYPERION, grant agreement no. 756962).

\section{REFERENCES}

(1) Green, M. A.; Ho-Baillie, A.; Snaith, H. J. The Emergence of Perovskite Solar Cells. Nat. Photonics 2014, 8 (7), 506-514.

(2) Kojima, A.; Teshima, K.; Shirai, Y.; Miyasaka, T. Organometal Halide Perovskites as Visible-Light Sensitizers for Photovoltaic Cells. J. Am. Chem. Soc. 2009, 131 (17), 6050-6051.

(3) Lee, M. M.; Teuscher, J.; Miyasaka, T.; Murakami, T. N.; Snaith, H. J. Efficient Hybrid Solar Cells Based on Meso-Superstructured Organometal Halide Perovskites. Science 2012, 338 (6107), 643-647.

(4) NREL. Best Research-Cell Efficiency Chart. https://www.nrel. gov/pv/cell-efficiency.html (accessed June 1, 2020).

(5) Leijtens, T.; Bush, K. A.; Prasanna, R.; McGehee, M. D. Opportunities and Challenges for Tandem Solar Cells Using Metal Halide Perovskite Semiconductors. Nat. Energy 2018, 3 (10), 828838

(6) Dunfield, S. P.; Bliss, L.; Zhang, F.; Luther, J. M.; Zhu, K.; Hest, M. F. A. M.; Reese, M. O.; Berry, J. J. From Defects to Degradation: A Mechanistic Understanding of Degradation in Perovskite Solar Cell Devices and Modules. Adv. Energy Mater. 2020, 10, 1904054.

(7) Stolterfoht, M.; Grischek, M.; Caprioglio, P.; Wolff, C. M.; Gutierrez-Partida, E.; Peña-Camargo, F.; Rothhardt, D.; Zhang, S.; Raoufi, M.; Wolansky, J.; Abdi-Jalebi, M.; Stranks, S. D.; Albrecht, S.; Kirchartz, T.; Neher, D. How To Quantify the Efficiency Potential of Neat Perovskite Films: Perovskite Semiconductors with an Implied Efficiency Exceeding 28\%. Adv. Mater. 2020, 32, 2000080.

(8) Jacobsson, T. J.; Correa-Baena, J.-P.; Halvani Anaraki, E.; Philippe, B.; Stranks, S. D.; Bouduban, M. E. F.; Tress, W.; Schenk, K.; Teuscher, J.; Moser, J.-E.; Rensmo, H.; Hagfeldt, A. Unreacted PbI2 as a Double-Edged Sword for Enhancing the Performance of Perovskite Solar Cells. J. Am. Chem. Soc. 2016, 138, 10331. 
(9) Du, T.; Burgess, C. H.; Kim, J.; Zhang, J.; Durrant, J. R.; McLachlan, M. A. Formation, Location and Beneficial Role of PbI2 in Lead Halide Perovskite Solar Cells. Sustain. Energy Fuels 2017, 1 (1), 119-126.

(10) Shi, B.; Yao, X.; Hou, F.; Guo, S.; Li, Y.; Wei, C.; Ding, Y.; Li, Y.; Zhao, Y.; Zhang, X. Unraveling the Passivation Process of PbI2 to Enhance the Efficiency of Planar Perovskite Solar Cells. J. Phys. Chem. C 2018, 122 (37), 21269-21276.

(11) Merdasa, A.; Kiligaridis, A.; Rehermann, C.; Abdi-Jalebi, M.; Stöber, J.; Louis, B.; Gerhard, M.; Stranks, S. D.; Unger, E. L.; Scheblykin, I. G. Impact of Excess Lead Iodide on the Recombination Kinetics in Metal Halide Perovskites. ACS Energy Lett. 2019, 4, 13701378.

(12) Jiang, M.; Wu, Y.; Zhou, Y.; Wang, Z. Observation of Lower Defect Density Brought by Excess PbI2 in CH3NH3PbI3 Solar Cells. AIP Adv. 2019, 9 (8), 085301.

(13) Park, B.; Kedem, N.; Kulbak, M.; Lee, D. Y.; Yang, W. S.; Jeon, N. J.; Seo, J.; Kim, G.; Kim, K. J.; Shin, T. J.; Hodes, G.; Cahen, D.; Seok, S. I. Understanding How Excess Lead Iodide Precursor Improves Halide Perovskite Solar Cell Performance. Nat. Commun. 2018, 9 (1), 3301.

(14) Ueoka, N.; Oku, T.; Ohishi, Y.; Tanaka, H.; Suzuki, A. Effects of Excess PbI2 Addition to $\mathrm{CH} 3 \mathrm{NH} 3 \mathrm{PbI} 3-\mathrm{xClx}$ Perovskite Solar Cells. Chem. Lett. 2018, 47 (4), 528-531.

(15) Yerramilli, A. S.; Chen, Y.; Sanni, D.; Asare, J.; Theodore, N. D.; Alford, T. L. Impact of Excess Lead on the Stability and PhotoInduced Degradation of Lead Halide Perovskite Solar Cells. Org. Electron. 2018, 59, 107-112.

(16) Gujar, T. P.; Unger, T.; Schönleber, A.; Fried, M.; Panzer, F.; van Smaalen, S.; Köhler, A.; Thelakkat, M. The Role of PbI2 in CH3NH3PbI3 Perovskite Stability, Solar Cell Parameters and Device Degradation. Phys. Chem. Chem. Phys. 2018, 20 (1), 605-614.

(17) Petrus, M. L.; Hu, Y.; Moia, D.; Calado, P.; Leguy, A. M. A.; Barnes, P. R. F.; Docampo, P. The Influence of Water Vapor on the Stability and Processing of Hybrid Perovskite Solar Cells Made from Non-Stoichiometric Precursor Mixtures. ChemSusChem 2016, 9 (18), 2699-2707.

(18) Ueoka, N.; Oku, T. Stability Characterization of PbI2-Added CH3NH3PbI3-XClx Photovoltaic Devices. ACS Appl. Mater. Interfaces 2018, 10 (51), 44443-44451.

(19) Shukla, S.; Shukla, S.; Haur, L. J.; Dintakurti, S. S. H.; Han, G.; Priyadarshi, A.; Baikie, T.; Mhaisalkar, S. G.; Mathews, N. Effect of Formamidinium/Cesium Substitution and $\mathrm{PbI} 2$ on the Long-Term Stability of Triple-Cation Perovskites. ChemSusChem 2017, 10 (19), 3804-3809.

(20) Liu, F.; Dong, Q.; Wong, M. K.; Djurišić, A. B.; Ng, A.; Ren, Z.; Shen, Q.; Surya, C.; Chan, W. K.; Wang, J.; Ng, A. M. C.; Liao, C.; Li, H.; Shih, K.; Wei, C.; Su, H.; Dai, J. Is Excess PbI2 Beneficial for Perovskite Solar Cell Performance? Adv. Energy Mater. 2016, 6 (7), 1502206.

(21) Tumen-Ulzii, G.; Qin, C.; Klotz, D.; Leyden, M. R.; Wang, P.; Auffray, M.; Fujihara, T.; Matsushima, T.; Lee, J.-W.; Lee, S.-J.; Yang, Y.; Adachi, C. Detrimental Effect of Unreacted PbI2 on the LongTerm Stability of Perovskite Solar Cells. Adv. Mater. 2020, 32, 1905035.

(22) Wang, H.-Y.; Hao, M.-Y.; Han, J.; Yu, M.; Qin, Y.; Zhang, P.; Guo, Z.-X.; Ai, X.-C.; Zhang, J.-P. Adverse Effects of Excess Residual $\mathrm{PbI} 2$ on Photovoltaic Performance, Charge Separation, and TrapState Properties in Mesoporous Structured Perovskite Solar Cells. Chem. - Eur. J. 2017, 23 (16), 3986-3992.

(23) Wang, Q.; Lyu, M.; Zhang, M.; Yun, J.-H.; Chen, H.; Wang, L. Transition from the Tetragonal to Cubic Phase of Organohalide Perovskite: The Role of Chlorine in Crystal Formation of CH3NH3PbI3 on TiO2 Substrates. J. Phys. Chem. Lett. 2015, 6 (21), 4379-4384

(24) Conings, B.; Babayigit, A.; Klug, M. T.; Bai, S.; Gauquelin, N.; Sakai, N.; Wang, J. T.-W.; Verbeeck, J.; Boyen, H.-G.; Snaith, H. J. A Universal Deposition Protocol for Planar Heterojunction Solar Cells with High Efficiency Based on Hybrid Lead Halide Perovskite Families. Adv. Mater. 2016, 28 (48), 10701-10709.

(25) Slotcavage, D. J.; Karunadasa, H. I.; McGehee, M. D. LightInduced Phase Segregation in Halide-Perovskite Absorbers. ACS Energy Lett. 2016, 1 (6), 1199-1205.

(26) Newman, J. A.; Schmitt, P. D.; Toth, S. J.; Deng, F.; Zhang, S.; Simpson, G. J. Parts per Million Powder X-Ray Diffraction. Anal. Chem. 2015, 87 (21), 10950-10955.

(27) Yakunin, S.; Dirin, D. N.; Shynkarenko, Y.; Morad, V.; Cherniukh, I.; Nazarenko, O.; Kreil, D.; Nauser, T.; Kovalenko, M. V. Detection of Gamma Photons Using Solution-Grown Single Crystals of Hybrid Lead Halide Perovskites. Nat. Photonics 2016, 10 (9), 585589.

(28) Roose, B.; Pathak, S.; Steiner, U. Doping of TiO2 for Sensitized Solar Cells. Chem. Soc. Rev. 2015, 44 (22), 8326-8349.

(29) Yin, J.; Cortecchia, D.; Krishna, A.; Chen, S.; Mathews, N.; Grimsdale, A. C.; Soci, C. Interfacial Charge Transfer Anisotropy in Polycrystalline Lead Iodide Perovskite Films. J. Phys. Chem. Lett. 2015, 6 (8), 1396-1402.

(30) Correa-Baena, J.-P.; Tress, W.; Domanski, K.; Anaraki, E. H.; Turren-Cruz, S.-H.; Roose, B.; Boix, P. P.; Grätzel, M.; Saliba, M.; Abate, A.; Hagfeldt, A. Identifying and Suppressing Interfacial Recombination to Achieve High Open-Circuit Voltage in Perovskite Solar Cells. Energy Environ. Sci. 2017, 10 (5), 1207-1212.

(31) Abdi-Jalebi, M.; Andaji-Garmaroudi, Z.; Cacovich, S.; Stavrakas, C.; Philippe, B.; Richter, J. M.; Alsari, M.; Booker, E. P.; Hutter, E. M.; Pearson, A. J.; Lilliu, S.; Savenije, T. J.; Rensmo, H.; Divitini, G.; Ducati, C.; Friend, R. H.; Stranks, S. D. Maximizing and Stabilizing Luminescence from Halide Perovskites with Potassium Passivation. Nature 2018, 555, 497.

(32) Roose, B.; Wang, Q.; Abate, A. The Role of Charge Selective Contacts in Perovskite Solar Cell Stability. Adv. Energy Mater. 2018, 9 (5), 1803140.

(33) Conings, B.; Drijkoningen, J.; Gauquelin, N.; Babayigit, A.; D’Haen, J.; D'Olieslaeger, L.; Ethirajan, A.; Verbeeck, J.; Manca, J.; Mosconi, E.; Angelis, F. D.; Boyen, H.-G. Intrinsic Thermal Instability of Methylammonium Lead Trihalide Perovskite. Adv. Energy Mater. 2015, 5 (15), 1500477.

(34) Hu, R.; Zhang, Y.; Paek, S.; Gao, X.-X.; Li, X.; Nazeeruddin, M. K. Enhanced Stability of $\alpha$-Phase FAPbI3 Perovskite Solar Cells by Insertion of 2D (PEA)2PbI4 Nanosheets. J. Mater. Chem. A 2020, 8 (16), 8058-8064.

(35) Saliba, M.; Matsui, T.; Seo, J.-Y.; Domanski, K.; Correa-Baena, J.-P.; Nazeeruddin, M. K.; Zakeeruddin, S. M.; Tress, W.; Abate, A.; Hagfeldt, A.; Gratzel, M. Cesium-Containing Triple Cation Perovskite Solar Cells: Improved Stability, Reproducibility and High Efficiency. Energy Environ. Sci. 2016, 9, 1989.

(36) de Mello, J. C.; Wittmann, H. F.; Friend, R. H. An Improved Experimental Determination of External Photoluminescence Quantum Efficiency. Adv. Mater. 1997, 9 (3), 230-232. 